\section{ASPECTOS LÓGICOS DEL PENSAMIENTO INTUITIVO}

\author{
Isabella Builes Roldán \\ Universidad EAFIT, Colombia \\ ORCID: https://orcid.org/0000-0002-9282-2233 \\ ibuiles@eafit.edu.co \\ Horacio Manrique Tisnés \\ Universidad EAFIT, Colombia \\ ORCID: https://orcid.org/0000-0002-7621-7391 \\ hmanriqu@eafit.edu.co
}

Cómo citar este artículo/Citation: Builes Roldán, I y Manrique Tisnés, H. (2018). Aspectos lógicos del pensamiento intuitivo. Arbor, 194 (788): a454. https://doi.org/10.3989/ arbor.2018.788n2014

Recibido: 26 septiembre 2017. Aceptado: 16 marzo 2018.

RESUMEN: En el presente artículo defendemos la hipótesis de que es posible encontrar en el pensamiento intuitivo una serie de características o leyes que dan cuenta de aspectos lógicos, distintos a la lógica simbólica clásica, y que involucran tanto el lado racional (intelectual) como emocional del ser humano. Para ello, proponemos una articulación entre autores provenientes de perspectivas diversas que, no obstante, argumentan a favor de la existencia de aspectos lógicos en el pensamiento intuitivo o en el pensamiento en general. En principio planteamos qué entendemos por aspectos lógicos, teniendo como base los términos lógica y logos, y diferenciamos los aspectos lógicos de un sistema lógico propiamente dicho. Posteriormente proponemos, siguiendo a Ramírez (2012), quien se basa en planteamientos psicológicos, psicoanalíticos, filosóficos y matemáticos, que existen dos tipos de lógica que consideramos se encuentran en la base del proceso de pensamiento intuitivo: una lógica primaria y una lógica secundaria, las cuales interactúan en un tercer tipo de lógica denominado lógica fractal. Finalmente proponemos una articulación entre la lógica fractal y el pensamiento intuitivo.

PALABRAS CLAVE: Pensamiento intuitivo; logos; lógica primaria; lógica secundaria; lógica fractal.

\section{LOGICAL ASPECTS OF INTUITIVE THINKING}

Copyright: (C) 2018 CSIC. Este es un artículo de acceso abierto distribuido bajo los términos de la licencia de uso y distribución Creative Commons Reconocimiento 4.0 Internacional (CC BY 4.0).

ABSTRACT: In this article we defend the possibility of finding in intuitive thinking a set of characteristics or laws which refer to logical aspects, which are different from classic symbolic logic, involving both the rational (intellectual) and the emotional side of human being. To this end, we propose an articulation between authors who, in spite of coming from different perspectives, argue in favor of the existence of logical aspects in intuitive thinking or in thinking in general. First, we develop what we mean by logical aspects, taking into account the concepts of logic and logos, and we establish a difference between a logical aspect and the logical system itself. After that, we propose following Ramirez (2012) who, based on psychological, psychoanalytic, philosophical and mathematical approaches, considered there to be two types of logic behind the process of intuitive thinking: primary logic and secondary logic, which interact giving place to a third kind of logic named fractal logic. Finally, we propose a link between fractal logic and intuitive thinking.

KEYWORDS: Intuitive thinking; logos; primary logic; secondary logic; fractal logic. 


\section{¿QUÉ SON ASPECTOS LóGICOS?}

Para defender la hipótesis de que es posible encontrar en el pensamiento intuitivo una serie de aspectos lógicos, es conveniente definir qué entendemos por estos y diferenciar un aspecto lógico de un sistema lógico.

El término lógico proviene del latín tardío logǐcus y

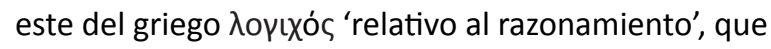

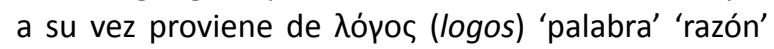
'lenguaje' 'pensamiento' (Corominas, 1980). Para Heráclito, el término logos estaba referido a una especie de fuerza que organiza o articula los elementos individuales del mundo en un todo coherente (Flew, 1979). De acuerdo con Galimberti (2002) logos es un término que en la Grecia antigua aludía al orden del mundo, que luego pasa a designar el orden del discurso, y posteriormente la razón.

Para Ramírez (2012) logos se refiere al paso a un nivel superior de articulación mediante la integración de un elemento novedoso, producto del azar, a lo ya existente, dando lugar así a una nueva reiteración. De acuerdo con este autor, es válido utilizar el término espíritu para designar las distintas formas de expresión que toma el logos, que podrían corresponderse con sus diferentes acepciones según el nivel de articulación o de "orden» al que nos estemos refiriendo; en principio, tal vez logos sea la acción de articular en general, posteriormente, el verbo, la palabra, que deviene en lenguaje y en razón (lógica), entendida esta como un nivel superior de expresión del logos.

Para explicar con mayor claridad el concepto de logos y su relación con distintos tipos de lógica, retomamos la propuesta de Ramírez (2012) sobre cuáles son los registros mediante los cuales se presentaría la realidad. Para abordar este tema, el autor plantea una conjetura sobre la evolución del cosmos: en principio existía el caos original todavía sin ninguna forma, esto es, "el real anterior a cualquier ser" (Ramírez, 2012, p. 118), en donde todo se transforma incesantemente, la energía pura, este es el registro real. En cierto punto, hay una acción que se sostiene en el tiempo, que permanece y permite cierta regularidad, esto es, una forma o figura (la materia o el ente, por ejemplo) que procede del caos originario pero se diferencia de este, en tanto que es energía condensada, este es el registro formal. Cuando hay una re-presentación de tales formas, es decir, "una repetición de la figura, de la presentación" (p. 118), una huella de lo real, hablamos del registro imaginario, es decir, del surgimiento de las imágenes. Lo imaginario puede ser físico, como en el caso de una sombra o del reflejo de un objeto, que no necesitan ser percibidos para existir; pero cuando las imágenes se asocian y se articulan según las leyes de la percepción y dejan una huella o representación fisiológica (cfr. Manrique Tisnés y de Castro Correa, 2016), hablamos de un imaginario animal; además, si nos referimos ya a imágenes mentales que requieren del psiquismo y de la relación con otros para ser evocadas, y que además se guían por estructuras lingüísticas, podemos nombrar esto como imaginario humano. El último registro se da gracias a la articulación de imágenes mentales determinadas por las leyes del lenguaje (cfr. Manrique Tisnés y de Castro Correa, 2016) o por las leyes culturales; el registro simbólico se refiere entonces a las representaciones (simbolizadas) de las representaciones (imaginarias), en tanto que estas permiten abstracciones como conceptos y significados; además este registro es el que da posibilidad a la comunicación humana.

Estos registros, aunque pueden diferenciarse teóricamente, se presentan como una mezcla inextricable en la experiencia cotidiana de la realidad, es decir, no es posible una forma sin energía, una imagen sin forma o una palabra sin una representación imaginaria, de hecho:

[...] toda realidad es una mezcla fractal de los respectivos registros: la realidad material es la unión de lo real y lo formal, la realidad animal agrega a esta realidad material lo imaginario sensorial: RFI [real, formal, imaginario]; y la realidad humana añade lo simbólico, RFIS [real, formal, imaginario, simbólico], ya que el hombre es un animal verbal, simbólico (Ramírez, 2012, p. 120).

Ahora bien, ¿cómo se relaciona el concepto de logos y los distintos tipos de lógica con estos registros? Para Ramírez (2012):

Podemos definir el logos como la acción de articular: la verbación, neologismo que tiene en cuenta su traducción latina, verbum, que en español, verbo, mantiene muy bien su doble significación de 'proceso' y de 'palabra'. También el vocablo articulación representa a la vez la acción de articular y su resultado. Pero el resultado, lo articulado, es más bien la acción conjunta de lo articulante, el logos o el Yang (lo creativo) de la filosofía china, con lo ya antes articulado, la ananké griega o el Yin chino (lo receptivo).

Hay un devenir en la verbación de lo caótico a lo elemental, de esto a lo primario (animal) y de allí a lo secundario (simbólico humano) para terminar en lo 
terciario (formalización y matematización). La secuencia evolutiva sería la siguiente: Formación $\rightarrow$ Combinación $\rightarrow$ Organización $\rightarrow$ Asociación $\rightarrow$ Simbolización $\rightarrow$ Verbalización $\rightarrow$ Teorización $\rightarrow$ Formalización (p. 248).

Si definimos logos como la acción de articular, como el principio que articula los elementos del mundo (la chispa o la causa), tal y como lo hacen Heráclito y Ramírez (2012), hemos de aceptar que es gracias a él como surge la forma, que hay posibilidad de iteración ${ }^{1}$, de devenir de caos a cosmos; aunque esto no está predeterminado, pues de la misma chispa (posibilidad creativa) puede surgir tanto el orden como el desorden (caos), que son dos caras de la misma moneda. Así las cosas, el devenir del logos va entonces desde la formación (constitución de un ente o de un elemento) o con-formación, por ejemplo cuando se constituye un átomo de hidrógeno; pasando por la combinación, por ejemplo cuando el átomo se combina con otro de hidrógeno y uno de oxígeno; a su vez estos cuando se organizan dan lugar a una molécula de agua, la cual es ya un elemento más complejo que cada uno de sus componentes; las propiedades intrínsecas del agua asimismo se combinan y se organizan con otras condiciones del medio y con aspectos azarosos para dar lugar a los más simples (y luego a los más complejos) organismos vivientes. En los animales hay leyes de asociación de las imágenes y de las representaciones que les permiten percibir y actuar en el mundo que los rodea, y en los humanos hay palabras que nombran imágenes, es decir, hay una simbolización del mundo y de las experiencias, una transposición del mundo a entes abstractos en principio mediante el simbolismo y posteriormente a través del orden significante. Cuando las palabras se expresan mediante la verbalización hay un paso más allá en tanto que la enunciación de palabras permite una descarga motora y una mayor articulación del pensamiento ya simbolizado (Zapata, 1995). Y además, si estas expresiones se articulan mediante razones para formar proposiciones basadas en leyes simbólicas de no-contradicción, llegamos al punto de la teorización. Finalmente cuando se vacía el contenido de estas proposiciones y se deja únicamente su estructura, se pueden establecer relaciones formales entre términos (por ejemplo fórmulas o matemas), es el nivel de la lógica formal, este procedimiento sería una expresión elevada de la formalización, el cual, de cierta forma ya ha sido "preparado" por los procesos anteriores que, aunque son formas de operación distintas, comparten con él el punto de tender hacia la articulación, aunque en fases distintas del ser, por eso:
El logos es la forma, es el espíritu de lo formal (el verbo); pero se hace carne cuando habla, cuando pertenece a un ser que habla; $y$ este es el surgimiento de lo simbólico: cuando alguien se dirige a un congénere no con una señal, un grito o una presencia, sino con una palabra: esto es, un signo; que es elemento de un lenguaje pero utilizado como señal de algo: incorpora lo imaginario y lo formal, con un sentido fundado en lo real como último referente (Ramírez, 2012, p. 248).

Es por lo anterior por lo que consideramos que en todas las fases del devenir del ser-físico-químico, biológico, psíquico y transindividual (psicosocial) (Simondon, 2009)- encontramos la expresión del orden, de la articulación: de distinta forma en cada una de ellas hay expresión del logos.

Teniendo en cuenta lo anteriormente descrito, lo que comúnmente designamos como lógica, que sería la lógica formal, es una forma de expresión de la razón, pero no la única, pues de hecho:

La razón es primero causa, determinación, cadena o sucesión de eventos y luego (muchísimo tiempo después) facultad humana de razonamiento (de pensamiento lógico). Primero logos y luego la lógica, después la logología y la matemática (Ramírez, 2012, p. 249).

Pero tampoco, según lo dicho, la lógica formal sería la única forma de expresión lógica: hay ya una lógica en lo imaginario (la cual comprende a su vez lo formal y lo real), que funciona mediante asociaciones por contigüidad y simultaneidad, y en general gracias a la sensibilidad, la percepción y las leyes del aprendizaje; es ajena a la contradicción y a la negación, por no ser todavía proposicional ni simbólica. Y por supuesto, hay también lógica en lo simbólico, que toma las representaciones imaginarias para hacer abstracción de ellas. De este modo:

Las imágenes (re-presentaciones sensoriales) son a su vez re-presentadas mediante palabras (representaciones de segundo orden). Se pasa de una lógica primaria, sin negación ni contradicción, a una lógica secundaria, simbólica, basada en el principio de no contra-dicción aristotélico (Ramírez, 2012, p. 200).

Sobre el término lógica, habría que aclarar que este ha sido usado en principio según dos acepciones: un uso técnico del término que alude a la lógica formal (la cual se explicará brevemente más adelante) y un uso "profano» del término; sobre este último aclara Quintanilla (1985):

Es el uso que hacemos de él cuando, por ejemplo, hablamos de «la lógica» de un determinado régimen 
político, o de la «la lógica» de las ciencias empíricas, o de «la lógica» de las relaciones de parentesco en el seno de una determinada comunidad, o de "la lógica» del lenguaje ordinario. En esta acepción, 'lógica' quiere decir a veces 'estrategia', a veces 'método', a veces 'conjunto de presupuestos, a veces 'hilo conductor', a veces simplemente 'aplicación de la lógica en sentido técnico', etcétera (p. 260).

Según la cita anterior, el término lógica parece adquirir un sentido más general, que alude a cierta dinámica específica, a una forma de operación o de funcionamiento ordenada según ciertas reglas o leyes. Este tipo de definición parece acercarse más en principio a la idea que se pretende transmitir al hablar aquí de aspectos lógicos del pensamiento intuitivo; no obstante, no consideramos que exista una brecha absoluta entre las formas lógicas "profanas» y las "técnicas», más bien son niveles distintos de la expresión del logos que, aunque no dejan de diferenciarse entre sí, comparten el punto de darle un orden o una forma de operación y de funcionamiento específico a cierto nivel de la realidad; que a su vez es susceptible de ser captado de una forma particular por las estructuras del pensamiento humano.

Para Gómez (2012) la lógica clásica se basa en una serie de principios de la razón, que determinan ya sea la esencia del ser (interpretación ontológica) o las posibilidades del conocimiento verdadero (interpretación gnoseológica). Estos principios son: el principio de identidad, según el cual todo ente es idéntico a sí mismo $(A \rightarrow A)$; el principio de no contradicción, que predica que es imposible ser y no ser al mismo tiempo y en el mismo sentido $\neg(A \wedge \neg A)$; el principio del tercer excluido, que plantea que necesariamente ocurre o un hecho o su contrario $(A \vee \neg A)$; el principio de bivalencia, según el cual un enunciado solo posee dos valores de verdad: lo absolutamente verdadero y lo absolutamente falso; el principio de reducción al absurdo, que dice que si de una tesis es posible deducir una contradicción, entonces dicha tesis es falsa; el principio de pseudo-Scoto, el cual anuncia que de una contradicción es posible deducir cualquier otro enunciado (indicando el riesgo de una contradicción para la racionalidad); y el principio de razón suficiente que predica que, para que un hecho acontezca, es necesario que haya una razón suficiente para que sea así y no de otro modo.

Los sistemas lógicos en general comparten ciertas características entre sí para ser considerados como tales, por ejemplo, que asignan un valor de verdad a las proposiciones, ya sea que partan de dos o más va- lores de verdad, que plantean unos signos o símbolos determinados de ese sistema, que tienen unas reglas de formación para determinar cuándo una fórmula es una estructura bien formada de ese sistema, que poseen reglas y definiciones que les permiten transformar una fórmula en otra, que parten de una teoría de demostración para derivar enunciados, entre otros elementos propios de un cálculo (cfr. Deaño, 2004). Según lo dicho hasta el momento en el presente trabajo no se pretende plantear un sistema lógico correspondiente al tipo de pensamiento intuitivo, sino más bien dar cuenta de una serie de leyes, características, fenómenos, etc., que se evidencian en este tipo de pensamiento según algunos autores; en consecuencia, nos distanciamos de las posturas que consideran que el pensamiento intuitivo es caótico, sin leyes, irracional o incomprensible. Es por esto por lo que las perspectivas que desarrollaremos a continuación las hemos designado como aspectos lógicos del pensamiento intuitivo.

\section{¿QUÉ ES PENSAMIENTO INTUITIVO?}

La intuición es un concepto complejo por sus diferentes acepciones y formas de comprensión. Etimológicamente, la intuición se asocia a la mirada y al acto de ver (Corominas, 1980). Históricamente, la intuición se ha entendido principalmente en dos sentidos: uno teológico, asociado a la bienaventuranza dada por Dios, y otro filosófico, asociado a la captación de datos mediante la percepción o a las ideas puras que surgen a partir de la razón (Builes, 2017).

Konrad Lorenz afirma que la intuición es "la captación inmediata de relaciones complejas" (Lorenz, 1993, p. 106), entendida "en el sentido de captar directamente la regularidad predominante a partir de un sinnúmero de hechos concretos" (Lorenz, 1993, p. 113). Además, Lorenz (1993) aclara que la intuición "es una función de la percepción en general y de la percepción gestáltica en particular y, por lo tanto, un proceso fisiológico totalmente natural" (Lorenz, 1993, p. 106). Así, considera que la intuición es condición necesaria para la ciencia, pues "no existe investigación de la naturaleza que carezca del todo de intuición" (Lorenz, 1993, p. 116; cfr. Bunge, 1996), y la considera complementaria al procedimiento de comprobación mediante inducción. Como características de la intuición menciona que es capacidad de síntesis de muchos elementos; en la vivencia subjetiva solo es posible captar el resultado de la misma, mas no el proceso por el que se llegó a este; lo percibido cobra el carácter de «verdad" y se toma por cierto, y por tanto no es corregible 
por la acción de la razón; y permite captar aspectos esenciales o constantes de los objetos más allá de lo contingente de los mismos (Lorenz, 1993).

Para Ramírez, Lopera, Zuluaga y Ortiz (2017), quienes se basan en este último autor, la intuición se entiende desde tres perspectivas: la facultad (intuición) de comprender los datos sin necesidad de razonamiento consciente, el proceso (intuir) no consciente, holístico y automático de conocimiento inmediato de una cosa mediante la asociación de saberes no conscientes; y el resultado (intuiciones), es decir, lo que deriva de este proceso que puede ser un estado de ánimo, un presentimiento, una ocurrencia o un saber consciente en forma de imágenes o palabras, el cual posee generalmente el carácter de una «verdad evidente» que no es corregible por la acción de la razón y lleva asociada una alta valencia afectiva. En este punto los autores resaltan la importancia de la formación y del análisis de la intuición y la depuración de los propios prejuicios, y nosotros resaltaríamos la importancia de hacer conscientes, hasta donde sea posible, las reglas o leyes inconscientes que guían el pensamiento intuitivo, lo cual podría favorecer el proceso de formación de la intuición².

Estos autores (Ramírez et al., 2017) describen entonces el pensamiento intuitivo como un proceso que parte de estímulos internos o externos al sujeto, los cuales son indicios que no se alcanzan a captar conscientemente. Entre estos estímulos se establecen asociaciones de forma automática, lo cual podemos interpretar como un proceso de análisis inconsciente de los mismos; y así:

Como efecto de todo este proceso, deriva una percepción holística (gestáltica), una síntesis o articulación de todos los elementos que están en juego. Esta síntesis se expresa como intuición, esto es, como un saber acerca de la naturaleza (orientación, cualidad, origen) del conjunto de estímulos que dio comienzo a todo el proceso, y que inicialmente se hallaban dispersos e inconexos (Ramírez et al., 2017, pp. 196-197).

\section{LÓGICA PRIMARIA}

Una de las disciplinas que describe las leyes del pensamiento inconsciente, que fundamentan también la intuición como la hemos comprendido en este artículo, es el psicoanálisis y sus elaboraciones en torno al proceso primario y secundario.

En La interpretación de los sueños Sigmund Freud (2010a) propone que el proceso primario se refiere a una forma de pensamiento en la cual se privilegian las imágenes en vez de los conceptos, no se diferencia entre lo percibido o lo conocido y lo representado o imaginado. Las representaciones se enlazan mediante ciertas categorías de asociación y se pasa de una imagen a otra cuando esta sirve para figurarse cierto aspecto de la vida psíquica. Freud menciona algunas de estas formas de asociación de las representaciones: mediante la simultaneidad, que tiende a reunir elementos y a presentar entre ellos un nexo cercano, dado que en algún momento estos se presentaron de forma simultánea; mediante la semejanza, referida a la concordancia entre dos elementos que pueden intercambiarse entre sí porque son similares; en el sueño por ejemplo, esta se representa por el «así como», en este punto entrarían también las relaciones por homofonía; mediante la comunidad o contigüidad, cuando dos elementos se muestran como vecinos, se suceden el uno al otro, lo cual evidencia que sus correspondientes pensamientos son cercanos en algún sentido psíquico; y la oposición, entendida como la tendencia a figurar un elemento mediante su opuesto o condensar dos opuestos en una sola unidad.

Lo anteriormente mencionado se basa en una concepción del psiquismo o del aparato psíquico dividido en dos sistemas o instancias, de los cuales el segundo deniega al primero el paso a la consciencia de ciertos contenidos penosos o merecedores de censura en general; en el caso del sueño, el segundo sistema desfigura estos contenidos penosos de tal modo que estos pueden mudar en otra cosa; por ejemplo, puede disfrazarlos convirtiéndolos en su contrario. El segundo sistema, el que critica o censura, mantiene relaciones más estrechas con la consciencia que el primer sistema, y por tanto se conecta con el obrar consciente y voluntario. La actividad del primer sistema se basa en la tendencia a disminuir las cantidades de excitación por medio de una descarga de las mismas y el segundo sistema produce una inhibición de esta descarga, aumentando el nivel de tensión "al proceso psíquico que conviene exclusivamente al primer sistema lo llamaré ahora proceso primario, y proceso secundario al que resulta de la inhibición impuesta por el segundo" (Freud, 2010a, p. 591). El proceso secundario hace uso del pensar y del razonar como un rodeo a la satisfacción que brindaría la descarga directa de la tensión, pasando así el psiquismo de estar regulado únicamente por el principio de placer a evidenciarse el principio de realidad.

Como otros elementos que hay que tener en cuenta en la lógica primaria se encuentran por supuesto las características que gobiernan el proceso primario, 
que Freud describe a modo de leyes generales que operan en el mismo; estas son: el desplazamiento, según el cual se desplazan cargas afectivas de ciertas representaciones a otras que inicialmente se encontraban débilmente cargadas; ocurre así una transferencia y un desplazamiento de las intensidades psíquicas hasta llegar a subvertir los valores psíquico-afectivos iniciales. También está el proceso de condensación, que consiste en concentrar varios elementos psíquicos en una sola representación o imagen; en el sueño, por ejemplo, se podrían representar varias palabras o nombres en una sola cosa u objeto. Además está la ausencia de contradicción y, por último, el miramiento por la figurabilidad o figuración plástica, entendida esta como la capacidad de figurarse una situación a partir de datos abstractos llevándolos a imágenes sensibles; de este modo, los pensamientos se transportan a huellas mnémicas visuales o acústicas.

En su artículo Lo inconsciente (2010b), Freud plantea que los procesos inconscientes poseen características y peculiaridades que contrarían directamente las propiedades de la consciencia, al pertenecer a dos sistemas distintos, como ya se dijo anteriormente. Estas características son: la ausencia de negación o de contradicción, que hace referencia a que en lo inconsciente hay contenidos investidos con mayor o menor intensidad, pero no hay negación entre ellos; la ausencia de temporalidad, es decir, los procesos inconscientes no están ordenados de acuerdo con el tiempo, no se modifican por el transcurso de este y en general no se relacionan con él; el proceso primario, es decir, la movilidad de las investiduras energéticas según las leyes de condensación y desplazamiento, y la sustitución de la realidad exterior por la psíquica, es decir, los procesos inconscientes se rigen por el principio de placer, no por el principio de realidad.

Jacques Lacan (Miller, 2010; Miller, 2015) también plantea algunos elementos importantes que hay que tener en cuenta en la discusión sobre la lógica primaria, tomando como referencia la teoría lingüística de Roman Jakobson, especialmente los polos metafórico y metonímico o eje paradigmático y eje sintagmático, puesto que para Lacan el inconsciente está estructurado como un lenguaje, lo cual quiere decir que los sujetos actúan muchas veces según una lógica del significante, es decir, guiados por las leyes del discurso y no según la realidad tal como esta es o tal cual se capta mediante la percepción. Lacan (Miller, 2010) parte también de la teoría del signo de Saussure, según la cual

[...] definiremos prudentemente el signo como una entidad que: 1) puede hacerse sensible y 2) para un grupo definido de usuarios señala una ausencia en sí misma. La parte del signo que puede hacerse sensible se llama, para Saussure, significante; la parte ausente, significado y la relación que mantienen ambas, significación (Ducrot y Todorov, 1974/1984, p. 121).

No obstante, Lacan da primacía al significante sobre el significado y sitúa su discusión en torno a la cadena significante, lo cual quiere decir que un significante remitirá siempre a otro significante y de este modo es posible producir sentidos.

En el Seminario de Jacques Lacan. Libro 5 Las formaciones del inconsciente (Miller, 2010) se explica que la cadena significante se encuentra permeada por los mecanismos de la metáfora y la metonimia, mecanismos que dan lugar a un mensaje que puede producir sentidos. Lo anterior es analizado a partir del tema de las formaciones de lo inconsciente, que explica Lacan así:

Hemos llegado a la noción de que en un discurso intencional donde el sujeto se presenta como queriendo decir alguna cosa, se produce algo que supera su voluntad, que se manifiesta como un accidente, una paradoja, incluso un escándalo (Miller, 2010, p. 53).

Retomando las leyes de condensación y desplazamiento de Freud, Lacan considera que la primera es una forma particular de la función de sustitución, de la metáfora, y agrega que:

En la relación de sustitución reside el mecanismo creador, la fuerza creadora, la fuerza de engendramiento, nunca mejor dicho, de la metáfora (Miller, 2010, p. 34).

Sustituir un significante es una forma de articulación de los significantes, y es allí donde la metáfora interviene produciendo significados. La dimensión metonímica se ejerce asociando elementos de acuerdo con los contextos en los que se presentan. Así:

La dimensión metonímica, en la medida en que puede participar en la agudeza, juega con los contextos y los empleos. Se ejerce asociando los elementos ya conservados en el tesoro de las metonimias. Una palabra puede estar vinculada de formas distintas en dos contextos diferentes, lo cual le aportará dos sentidos completamente distintos. Tomándola en un cierto contexto con el sentido que tiene en otro, estamos en la dimensión metonímica (Miller, 2010, p. 64).

El deseo del sujeto se modifica entonces de acuerdo con su relación con el significante. Que el deseo no esté totalmente determinado por la necesidad hace que los objetos de este estén sometidos a sustituciones y a desplazamientos (metáforas y metonimias) propias de la función de la palabra. 
De acuerdo con lo dicho, lo que Freud llama proceso primario es para Lacan lo que está marcado y estructurado por el lenguaje y el modo de funcionamiento primario de este, que da lugar a las formaciones del inconsciente. De este modo, los sueños, los lapsus, los síntomas, entre otros son sustituciones (metáforas) y desplazamientos (metonimias) de deseos reprimidos. Según Ducrot y Todorov (1974/1984) se podría resumir lo dicho hasta el momento mediante dos fórmulas que plantea Lacan:

La condensación es una metáfora donde se dice como sujeto el sentido reprimido de su deseo, y el desplazamiento es una metonimia donde se marca aquello que constituye el deseo, deseo de otra cosa que siempre falta (Miller, 2010, p. 396).

En El Seminario de Jacques Lacan. Libro 6. El deseo y su interpretación, Lacan complementa lo anteriormente planteado diciendo que el deseo no puede comprenderse por referencia a objetos ni tampoco bajo el esquema predeterminado de estímulo-respuesta; como ejemplo menciona lo siguiente:

Si cosquillean la planta de las patas de una rana, ésta responde haciendo cierta relajación muscular. Pero cuando está en juego la subjetividad capturada por el lenguaje, hay emisión, no de un signo, sino de un significante (Miller, 2015, p. 20).

No es un signo lo que se emite, puesto que por definición este es una entidad que hace referencia a un objeto extralingüístico que este representa, mientras que un significante a lo que refiere es a otro significante dentro de la cadena misma. El deseo es entonces explicado por Lacan en los siguientes términos:

Entre el lenguaje pura y simplemente requisitivo de la demanda y aquel en que el sujeto responde a la pregunta acerca de lo que quiere y se constituye con respecto a lo que es hay un intervalo. En ese intervalo se produce lo que se denomina deseo (Miller, 2015, p. 192).

De acuerdo con lo anterior los sujetos, más que guiarse por algún tipo de objetividad total o de realidad, pueden desear en tanto que tienen en cuenta la sustitución de un significante por otro (condensación, metáfora) y el desplazamiento de un objeto a otro que falta dentro de la cadena significante (metonimia).

Desde una perspectiva filosófica y fenomenológica, también Ricœur (1986) reconoce la existencia de un tipo de pensamiento involuntario y espontáneo que realiza una suerte de "improvisación" por sí mismo y sin necesidad de consciencia, y se guía por las categorías básicas de semejanza y contraste ${ }^{3}$. Sobre esto plantea que:
Dicha improvisación del pensamiento se expresa en particular en la asociación de ideas, y más precisamente en la asociación por semejanza y contraste [...]. Bain ya había presentido que esta asociación por semejanza y contraste ocultaba todo el pensamiento espontáneo, como si una necesidad de reconocer las cosas y de asimilarlas, y una necesidad de acentuarlas oponiéndolas estuvieran dotadas de vida propia y se adelantaran al pensamiento reflexivo en sus síntesis y sus discriminaciones. Se trata de lo que autores como Renovier y Hamelin han visto perfectamente: la asociación llamada por semejanza y contraste resume de manera grosera toda la diversidad de relaciones cuyo edificio forma la armadura misma del pensamiento; y tales relaciones son vivientes; actúan espontáneamente antes aún de ser percibidas. Algo razonable opera sin que razonemos (Ricœur, 1986, p. 320).

\section{LÓGICA SECUNDARIA}

Una forma de describir las formas de pensamiento simbólicas o secundarias es desde la perspectiva ontogenética-evolutiva del ser humano.

En la vía de conocer este devenir del pensamiento humano, Piaget (1970/1972) plantea una epistemología genética, la cual implica procesos biológicos, psicológicos y también lógicos, y como su nombre lo indica, requiere un proceso gradual de desarrollo en el ser humano. Este autor considera que entre los cuatro y los siete años se da una sucesión en la adquisición de conocimientos y habilidades: el infante humano en primer lugar se vuelve capaz de hacer seriaciones, es decir, de establecer relaciones de orden (primero $A$, luego $B$, etc.), y en segundo lugar forma agrupaciones o clases ( $A$ y $A^{\prime}, B$ y $B^{\prime}$, etc.). También, con relación a la percepción, se da un predominio inicial de relaciones topológicas (de vecindad, continuidad, cierre, posiciones en relación con las fronteras, etc.), y solo posteriormente se comprenden las relaciones entre segmentos o figuras separadas a partir de la interiorización de las nociones de espacialidad según la geométrica y la métrica.

Con relación al asunto de la experiencia, leemos en Piaget (1970/1972) que según la tradición filosófica empirista, todo conocimiento proviene necesariamente de la experiencia, sin embargo, para este autor, aunque esta brinda claramente unas bases para el conocimiento de los objetos del mundo, pues es la que permite descubrir las propiedades físicas de los mismos, existen también nociones abstractas que se van desarrollando en el infante a partir de la experiencia; más específicamente, a partir de las acciones 
que el infante realiza sobre los objetos, este va abstrayendo propiedades que conllevan la comprensión de unas operaciones y formas de coordinación más allá del objeto mismo. Un ejemplo de una noción que se desarrolla gracias a procesos lógicos es la noción de conservación, según la cual a partir de los seis o siete años el niño es capaz de identificar la conservación de la cantidad de objetos o de materia independientemente de los cambios perceptivos que tenga, gracias a tres procesos: la identificación, que permite reconocer que se mantiene la cantidad de un líquido por ejemplo aunque este se cambie de recipiente; la reversibilidad simple, que permite reconocer que se puede volver a un estado inicial del objeto o de la materia; y la compensación de las transformaciones relativas, que permite reconocer que ciertas características, el alto de un recipiente, por ejemplo, pueden compensarse con otras, el ancho de otro recipiente, por ejemplo. La experiencia física consistiría en actuar sobre los objetos para generalizar conocimiento; la experiencia lógicomatemática obtiene conocimiento a partir de una abstracción de la acción sobre los objetos, y no de los objetos como tales, pues en la acción se le agregan al objeto caracteres que este no poseía antes, los cuales se añaden a sus propiedades anteriores.

Ahora, según lo dicho, ¿qué lugar ocupa el estudio de la lógica en el pensamiento? Si se entiende la lógica como una serie de universales inmutables que dan cuenta sobre lo real, no podríamos decir que se ocupe en ninguna medida del pensamiento y de la adquisición de conocimiento, dado que, como se dijo, este es un proceso; sin embargo, si entendemos que el estudio de la lógica se ocupa principalmente de las operaciones deductivas e inductivas y de su formalización en estructuras, podría relacionarse directamente con las operaciones de pensamiento y del conocimiento en general en el proceso de desarrollo del ser humano; de acuerdo con lo dicho:

Entonces el universo no es conocido por el hombre más que a través de la lógica de las matemáticas, producto de su espíritu, pero no puede comprender cómo ha construido las matemáticas y la lógica si no se estudia a sí mismo psicológica y biológicamente, es decir, en función del universo entero (Piaget, 1970/1972, p. 110).

Piaget habla en este punto refiriéndose a la lógica simbólica únicamente; sin embargo, sugiere más adelante (1970/1972, p. 130) que las raíces de esta lógica deberían buscarse en estructuras sensorio-motrices previas al lenguaje que también poseen relaciones de orden y que coordinan las acciones; en este punto se podrían incluir otros planteamientos sobre la existencia de una lógica de pensamiento intuitivo distinta a la lógica simbólica.

Luego la adquisición del pensamiento lógico formal de acuerdo con Piaget (1999) consiste no solamente en la capacidad de realizar una serie de operaciones abstractas, sino en adquirir un estado de consciencia distinto (acompañado de sentimientos y conductas), que se caracteriza por cierta "obligación social" de tener un pensamiento lógico, no contradictorio, lo cual se constituiría en una exigencia intelectual, social y moral.

\section{LÓGICA FRACTAL}

De acuerdo con Ramírez (2012), quien a su vez se basa en Aristóteles, Freud, Piaget, entre otros autores de diferentes disciplinas:

El ser humano posee un sistema secundario (de signos), fundamentado en el lenguaje y las palabras, que le permite razonar. Puede analizar desde una perspectiva lógica (aristotélica, racional) las consecuencias de un acto; pero también puede tener en cuenta las motivaciones afectivas, pulsionales, emocionales, imaginarias o inconscientes: es lo que llamaríamos razonabilidad, que no estaría basada solamente en una lógica simbólica ni tampoco solo en una lógica imaginaria, sino en la dialéctica de ambas (Ramírez, 2012, p. 46).

En la cita anterior se evidencia la posición que se quiere transmitir, la lógica fractal incluye entonces ambas perspectivas lógicas, la simbólica, bivalente y basada en leyes formales, y la primaria, basada en unas leyes imaginarias, automáticas y generalmente no conscientes, aunque esta última no se considera de ninguna manera irracional.

«Fractal» es un concepto matemático propuesto por Benoît Mandelbrot en el ámbito de la geometría que proviene del latín fractus: irregular. Talanquer (1996), Ramírez (2012) y Ramírez et al. (2017) retoman este término para referirse a objetos (o realidades) que poseen tres características: la dimensión fraccionaria o pertenencia a dimensiones no enteras; la autosimilaridad, referida a la iteración de formas simples en varias escalas; y la porosidad, como la capacidad de interpenetración con otros objetos o realidades (cfr. Wagensberg, 2013).

De acuerdo con lo dicho, ¿cómo sustentar la idea de la existencia de una lógica fractal? Si hemos dicho, con Ramírez (2012), que la realidad se puede comprender según la evolución de cuatro registros (real, formal, imaginario y simbólico), pero que en la experiencia cotidiana estos se presentan de forma simultá- 
nea a modo de una mezcla inextricable (fractal) de los mismos, es posible que la lógica, entendida como un modo de expresión del logos que toma la forma de la razón humana, también se pueda comprender separando los distintos tipos de lógica (como hemos hecho en este capítulo: una lógica primaria y una lógica secundaria, por ejemplo); pero a su vez habría que aceptar que estos tipos de lógica no son excluyentes entre sí, de hecho son complementarios, y la experiencia cotidiana se presenta como una mezcla de estos, en la cual es difícil establecer una barrera absoluta entre un modo de funcionamiento lógico y otro ${ }^{4}$.

También es por lo anterior por lo que el pensamiento intuitivo contiene aspectos de lógica primaria y secundaria pues, aunque tiene un sustento importante en la lógica imaginaria (en las leyes de la percepción, de la sensación, del aprendizaje, del "instinto"), estas han sido modificadas y están atravesadas por la dimensión simbólica de la realidad humana. De acuerdo con Ramírez (2012):

Hay una lógica primaria que es la lógica de lo imaginario, basada en la contigüidad (desplazamiento, diacronía, metonimia, eje sintagmático) y en la simultaneidad (condensación, sincronía, metáfora, eje paradigmático, semejanza). La que llaman lógica femenina, soporte de la intuición, formalizada por los matemáticos contemporáneos como lógica sin negación. Es multívoca, polisémica, y para Freud determina los procesos inconscientes.

Hay una lógica secundaria, lógica simbólica, basada en el principio de no contradicción, llamada usualmente lógica bivalente o aristotélica. Es la lógica clásica fundamentada en la ley del tercero excluido y en la negación. El discurso científico está basado en ella y se utiliza en la vida cotidiana cuando queremos que el discurso sea riguroso, racional: su límite ideal es la lógica formal. Algunos la asocian con lo masculino. Es unívoca, con un sentido único estructural o sintáctico que permite múltiples significaciones.

La lógica cotidiana (de hombres y mujeres) raras veces se ubica exclusivamente en uno de los dos campos anteriores. Es a veces primaria y a veces secundaria, y la mayor parte del tiempo es una mezcla inextricable: por un momento funciona formalmente, unívoca, consistente, para saltar en seguida a otro sentido homofónico, similar o por mera alusión. Por eso la llamamos lógica fractal, porque en ella lo primario y lo secundario están mezclados como el agua y la arena o la esponja y el aire. Es la lógica corriente (Ramírez, 2012, p. 123).
Consideramos que es a causa de lo anterior por lo que nos hemos topado con las categorías asociativas básicas de semejanza y contigüidad en las teorías que hemos presentado hasta el momento y otras que no hemos mencionado, las cuales se modifican según la complejidad del fenómeno en cuestión, ya sea el lenguaje, el pensamiento, el funcionamiento neural o, por otra parte, lo inconsciente: en las disciplinas del lenguaje están el eje paradigmático y el eje sintagmático; en el psicoanálisis freudiano la condensación y el desplazamiento; en el psicoanálisis lacaniano la metáfora y la metonimia; en la neurología, las relaciones topográficas y topológicas entre las neuronas ${ }^{5}$, en la psicología del pensamiento, las teorías sobre la semejanza, la metáfora, la inducción y la analogía ${ }^{6}$, entre otras.

El anterior argumento puede sustentarse tomando como base el principio de isomorfismo (iso: 'igual'; morphé: 'forma') el cual retoma también la teoría de la Gestalt (Mitri, 2002).

Este concepto proveniente de las matemáticas, designa la correspondencia uno a uno entre los elementos de dos sistemas o conjuntos, por lo que resulta que también se corresponden las operaciones y relaciones de esos sistemas (Mitri, 2002, p. 12).

La teoría de la Gestalt lo utiliza para indicar que existen correlaciones dinámicas entre los distintos niveles de la realidad: físico, biológico y psicológico, y para resaltar la interdependencia entre estos.

Así, los procesos físicos, somáticos y mentales correspondientes a un mismo fenómeno, más allá de su diferencia en cuanto a sus dominios y a los elementos heterogéneos, poseerían una estructura funcional semejante entre sí (Mitri, 2002, p. 12).

En este caso, según lo que hemos dicho, habría un isomorfismo entre el funcionamiento neuronal, los procesos psicológicos de pensamiento y el lenguaje o funcionamiento lingüístico, entre otros aspectos, en tanto que estos aspectos comparten categorías afines, que pueden diferenciarse teóricamente, pero en la realidad se presentan a modo de una mezcla inextricable, fractal, de las mismas.

Para dar un ejemplo sencillo de la lógica fractal (y en este caso, de una intuición fractal) se podría pensar en una situación de toma de decisiones, tal como la elección de un candidato presidencial, en la cual se combinan aspectos imaginarios, emocionales (como el aspecto físico, la forma de expresarse, entre otros) que nos llevan a descartar ciertas opciones de candidatos, y 
luego cuando hemos de elegir entre solo dos restantes podemos analizar desde una perspectiva racional cuáles son las posibles consecuencias de elegir a uno o a otro; o también un caso cotidiano, en el cual se puede analizar una situación desde una perspectiva lógica y simbólica para pasar en otro momento a plantear semejanzas por homofonía o contigüidad entre palabras o expresiones. Ramírez (2012) plantea que la intuición es fractal, en tanto que implica captaciones y ocurrencias holísticas y sintéticas, pero para su formación requiere del análisis de los prejuicios sedimentados en el propio discurso.

\section{CONCLUSIONES}

Hemos identificado en el pensamiento intuitivo dos tipos de lógica: primaria y secundaria. La primera es la lógica sin negación, que está basada en las categorías básicas de contigüidad y simultaneidad, la segunda es la lógica aristotélica basada en la no contradicción, esencial en el pensamiento humano. Estas dos interactúan entre sí de tal forma que no es posible decir que la intuición es únicamente una percepción o un instinto pues, aunque encuentra allí su soporte, es un fenómeno humano complejo determinado también por leyes de funcionamiento lingüístico como la metáfora y la metonimia. Por tanto, es más conveniente hablar de una lógica fractal, que es una mezcla de estos dos tipos de lógica, y que influye en el proceso de pensamiento, que puede guiarse más desde lo primario o lo secundario, según se trate de pensamiento intuitivo o de pensamiento deliberado.

\section{AGRADECIMIENTOS}

Los autores agradecemos al profesor Carlos Arturo Ramírez por su disposición para revisar el texto, realizar comentarios críticos y conversar al respecto. También a la Universidad EAFIT de Medellín, Colombia, por financiar el proyecto de investigación titulado Aspectos lógicos del pensamiento intuitivo y sus implicaciones en la toma de decisiones, del cual deriva el presente artículo.

\section{NOTAS}

1. Logos se combina con ananké, la 'necesidad' o la 'repetición', para dar lugar tanto a la iteración como al surgimiento de algo novedoso a partir de esta.

2. En el Informe del Banco Mundial sobre el desarrollo mundial del año 2015 se hace referencia a algunas perspectivas psicológicas contemporáneas como la teoría de los modelos mentales (cfr. Johnson-Laird, 1983) para referirse al modo de pensamiento de los seres humanos, quienes tienen limitaciones cognitivas a la hora de tomar decisiones e interpretan la realidad a partir de los modelos que construyen del mundo; por esta razón, los autores de este texto resaltamos la importancia de estudiar los aspectos relacionados con el pensamiento intuitivo con el fin de intervenir sobre ellos teniendo como meta el desarrollo humano individual y por ende de los países (cfr. Banco Mundial, 2015).

3. También Cassirer (1998) encuentra características similares en sus estudios sobre el pensamiento mítico, el cual no se contrapone al pensamiento científico. Así, este autor reconoce la importancia de la imagen en el pensamiento mítico y como formas de funcionamiento de este plantea la asociación por contigüidad y la tendencia a la síntesis, entre otras.

4. Este argumento, si se amplía hablando de las clases y los niveles de la realidad y de la relación de estos con las teorías científicas, puede llegar a ser una crítica al dogmatismo y al reduccionismo en la ciencia (cfr. Manrique Tisnés y de Castro Correa, 2016).

5. Véase Damasio (1996). En este punto es importante aclarar que en el ser humano tanto la lógica primaria como la secundaria tienen un fundamento biológico y fisiológico en cuanto al funcionamiento neuronal, a la formación de representaciones mentales, y a los procesos emocionales y adaptativos (Cfr. Changeux, 1985; Damasio, 1996).

6. Cfr. Holyoak y Morrison (2005).

\section{BIBLIOGRAFÍA}

Builes, I. (2017). Aproximación a algunas propuestas filosóficas y psicológicas sobre el concepto de intuición y su relación con la lógica del pensamiento. En: Cardona, P. y Cuartas J. M. (eds.). Pluralidad y escritura. Medellín: Editorial EAFIT, pp. 125-144.

Bunge, M. (1996). Intuición y razón. Buenos Aires: Editorial Sudamericana.
Cassirer, E. (1998). Filosofía de las formas simbólicas (tomo II. El pensamiento mítico). México: Fondo de Cultura Económica.

Changeux, J. P. (1985). El hombre neuronal. Madrid: Espasa-Calpe.

Corominas, J. (1980). Breve diccionario etimológico. Madrid: Gredos.
Damasio, A. R. (1996). El error de Descartes. La emoción, la razón y el cerebro humano. Santiago de Chile: Editorial Andrés Bello.

Deaño, A. (2004). Introducción a la lógica formal. Madrid: Alianza editorial.

Ducrot, O. y Todorov, T. (1974/1984). Diccionario enciclopédico de las ciencias del lenguaje. México DF: Siglo XXI editores. 
Flew, A. (1979). A dictionary of philosophy. Londres: PanBooks.

Freud, S. (2010a). Obras completas: La interpretación de los sueños. Buenos $\mathrm{Ai}$ res: Amorrortu.

Freud, S. (2010b). Obras completas: Lo inconsciente. Buenos Aires: Amorrortu.

Galimberti, U. (2002). Diccionario de psicología. México DF: Siglo XXI editores.

Gómez, R. A. (2012). Breves tratados de lógica y argumentación. Medellín: Editorial EAFIT.

Holyoak, K. J. y Morrison, R. G. (eds.) (2005). The Cambridge handbook of thinking and reasoning. Cambridge: Cambridge University Press.

Johnson-Laird, P. (1983). Mental models. Towards a cognitive science of language, inference and consciousness. Cambridge: Cambridge University Press.

Lorenz, K. (1993). La ciencia natural del hombre. "El manuscrito de Rusia» (1944-1948). Introducción al estudio comparado del comportamiento. BarceIona: Tusquets.

Manrique Tisnés, $\mathrm{H}$. y de Castro Correa, $\mathrm{A}$ (2016). Realidad, teoría y conmensurabilidad: reflexiones en torno a las modas intelectuales en psicología. Revista CES Psicología, 9 (1), pp. 65-88. https:// doi.org/10.21615/cesp.9.1.5
Miller, J.-A. (ed.) (2010). El Seminario de Jacques Lacan. Libro 5. Las formaciones del inconsciente 1957-1958. Buenos Aires: Paidós.

Miller, J.-A. (ed.) (2015). El Seminario de Jacques Lacan. Libro 6. El deseo y su interpretación 1957-1958. Buenos Aires: Paidós.

Mitri, J. (2002). Sobre la gestalttheorie Posición y función de la psicología de la Gestalt en el pensamiento contemporáneo. En: Lodieu, M. y Scaglia, H. (comps.) Construcciones en psicología. Buenos Aires: Proyecto editorial, pp. 1-21.

Piaget, J. (1999). La psicología de la inteligencia. Barcelona: Crítica.

Piaget, J. (1970/1972). Psicología y epistemología. Buenos Aires: Emecé Editores.

Quintanilla, M. A. (1985). Diccionario de filosofía contemporánea. Salamanca: Sígueme.

Ramírez, C. A. (2012). La vida como juego existencial. Ensayitos. Medellín: Editorial EAFIT.

Ramírez, C., Lopera, J., Zuluaga, M. y Ortiz, J. (2017). El método analítico (Volumen I. Formalización teórica). Bogotá: San Pablo.

Ricœur, P. (1986). Lo voluntario y lo involuntario II. Poder, necesidad y con- sentimiento. Buenos Aires: Editorial Docencia.

Simondon, G. (2009). La individuación. A la luz de las nociones de forma y de información. Buenos Aires: Cactus y La Cebra Ediciones.

Talanquer, V. (1996). Fractus, fracta, fractal. Fractales, de laberintos y espejos. México: Fondo de Cultura Económica.

Wagensberg, J. (2013). La rebelión de las formas. $O$ cómo perseverar cuando la incertidumbre aprieta. Buenos Aires: Tusquets.

Zapata, L. (1995). La verbalización: de la curación por la palabra al método psicoanalítico. [Monografía de pregrado inédita]. Medellín: Universidad de Antioquia.

\section{Recursos web}

Banco Mundial. (2015). Informe sobre el desarrollo mundial 2015: Mente, sociedad y conducta, cuadernillo del "Panorama general". Banco Mundial: Washington DC. Licencia: Creative Commons de Reconocimiento CC BY 3.0 IGO. [En línea]. Disponible en https:// openknowledge.worldbank.org/bitstream/handle/10986/20597/928630 WDR0v20000Box385381B00PUBLIC0. pdf? sequence $=30$ \&isAllowed $=y$ 